NOTAS NOTES 



\title{
VALIDACIÓN: CONSTRUCCIÓN DE UN CONCEPTO DE TEORÍA GENERAL DEL DERECHO *
}

\author{
Jesús Delgado Echeverría ** \\ Universidad de Zaragoza
}

RESUMEN: Este trabajo pretende introducir un concepto nuevo en la teoría general del derecho, el de validación, relacionado con los de validez, vigencia, fuerza de obligar, invalidación y convalidación. Las normas validadas en un sistema forman un subconjunto que no coincide con las válidas, con las vigentes ni con las convalidadas. En el texto se ofrece un concepto riguroso de invalidación mediante definiciones formales. De momento, puede servir decir que el concepto de validación denota un tipo de actos que operan sobre otros actos o normas afirmando o presuponiendo su validez con arreglo a ciertos criterios y dotándolos de fuerza de obligar provisional, mientras no sean declarados inválidos; a la vez que restringen las posibilidades de que tal declaración de invalidez tenga lugar. Se muestra la presencia de tales actos de validación y su necesidad institucional en los ordenamientos actuales, tanto respecto de normas generales (por ejemplo, promulgación, publicación) como de actos de particulares (por ejemplo, fe pública notarial, inscripciones registrales). Por último, se relaciona la validación con la presunción de validez.

Palabras clave: validación, validez, vigencia, fuerza de obligar, invalidación, convalidación, presunción de validez.

ABSTRACT: This work seeks to present a new concept of the general theory of law, that of validation, related to those of validity, legal force, binding force, invalidation and convalidation. Validated norms in a legal system constitute a subset which neither coincides with valid norms, nor with those in force, nor either with those which have been convalidated. The text offers us a rigorous concept of invalidation by means of formal definitions. For now, it is enough to say that the concept of validation indicates a type of actions which operate on other actions or norms, declaring or presupposing their validity in accordance with certain criteria, and endowing them with temporary binding force, as long as they are not declared invalid; while, at the same time they lessen the possibilities that such a declaration of invalidity should take place. The presence of such validation actions and their institutional necessity in the current legal systems is shown, with regard to general norms (for example, enactment, publication) as well as with regard to actions performed by private individuals (for example, notary's public affidavits, Registrar's entries). Lastly, validation is associated with the presumption of validity.

Keywords: validation, validity, legal force, binding force, invalidation, convalidation, presumption of validity.

Quia bonum sit valere CICERÓN, De finibus, 4.62

* Fecha de recepción: 2 de diciembre de 2008. Fecha de aceptación: 18 de diciembre de 2008.

** Trabajo realizado en el marco de los proyectos SEJ2005-05790 y DER2008-01669/JURI. Agradezco a M. ATIENZA y a J. AguiLÓ sus valiosas observaciones a una redacción previa. También me he beneficiado de la discusión de las ideas centrales en el Seminario del Grupo de Investigación «Nulidad» en la Universidad de Zaragoza. 


\section{VALIDEZ, JUICIO DE VALIDEZ, ACTOS DE VALIDACIÓN}

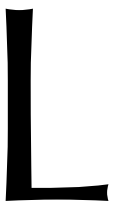

a validez de un acto no es una propiedad del mismo, sino una relación entre el acto y la norma que atribuye el poder para realizarlo y señala sus condicionamientos y límites. Un acto es válido en un sistema normativo siempre que forme parte del mismo una norma atributiva de poder conforme a la cual el acto sea válido; en otro caso, el acto no es válido.

Pero la relación del acto con la norma atributiva de poder sólo puede afirmarse mediante un juicio que requiere justificación. Este «juicio de validez» es siempre más o menos incierto, pues tiene como presupuesto la interpretación de (todas) las normas del sistema ${ }^{1}$.

Diferentes sujetos (las partes, terceros, expertos, funcionarios, jueces...) pueden mantener diferentes opiniones razonables sobre la validez del acto. Sólo la «cosa juzgada» puede poner fin a la incertidumbre y, entonces, no con valor de «verdad», sino como última palabra revestida de autoridad, que excluye cualquier juicio posterior sobre la validez relevante en el sistema.

Ahora bien, en la práctica social del Derecho se cuenta con la validez de los actos que se presenten con ciertas características, de modo que tienen fuerza de obligar y producen todos sus efectos mientras no sean objeto de invalidación por los jueces tras el debido proceso. Limitar las oportunidades de juicios de invalidez relevantes en el sistema contribuye a la credibilidad del acto como válido y a aumentar la confianza de sus autores y de los terceros en el cumplimiento y efectos del mismo.

En la experiencia jurídica, pasada y presente, observamos la presencia de artificios muy variados que contribuyen a estabilizar las expectativas sobre la obligatoriedad de los actos jurídicos. Se trata, dicho ahora de manera muy general, de signos o actos de las partes, de terceros o de autoridades, referidos a otros actos jurídicos y que tienden a dotarlos de mayor fuerza de obligar. A estas formas o formalidades añadidas con dicha finalidad, así como a los resultados de las mismas, podemos llamar genéricamente validación.

En el presente trabajo, después de considerar otras posibilidades, propongo un concepto más estricto de validación, que no incluye todos los artificios dirigidos a aumentar la fuerza social de obligar de las normas (su eficacia, si se prefiere), sino sólo aquellos que operan formalmente mediante la restricción de las acciones y recursos jurídicos que tienen por objeto la invalidación de las normas (por ejemplo, limitación de jurisdicciones, procedimientos, legitimados, plazos, carga de la prueba).

Este trabajo es, por tanto, sustancialmente, una propuesta de un concepto específico de validación que entiendo puede rendir interesantes servicios en la teoría general del derecho y en la dogmática de algunas de sus ramas; concepto referido tanto a los actos de los particulares como a los de los poderes públicos productores de normas generales.

\footnotetext{
${ }^{1}$ La relación con todas las normas del sistema la enfatiza, por ejemplo, PEÑA FREIRE (1999: 106-107): «[1]a validez/legalidad es una relación de corrección entre una norma y un ordenamiento jurídico»... «[S]ólo la relación de congruencia con todas y cada una de las normas del ordenamiento es condición suficiente de validez».
} 
En la teoría general de la norma, el concepto de validación contribuye a explicar y aclarar los problemas que suelen plantearse como de «inexistencia» de las normas en cuya producción no se han observado requisitos mínimos de competencia y procedimiento, o la cuestión del estatus de las normas «irregulares» (en particular por contradecir normas superiores) no invalidadas por el juez competente. Se trata de los importantes problemas que están detrás de la insatisfactoria propuesta de KELSEN de una «cláusula alternativa tácita». Se defenderá que las normas validadas tienen plena fuerza de obligar (validez, Geltung, en el sentido de obligatoriedad, Verbindlichkeit) mientras no sean invalidadas.

Respecto de los actos de los particulares, la validación se manifiesta de muy diversos modos, relacionados con la forma de los mismos y otras formalidades. Son fenómenos destacados de validación la intervención notarial y la inscripción en ciertos registros. Los actos (contratos, testamentos...) validados tienen fuerza de obligar que sólo podrán negar los jueces y, acaso, algunos funcionarios en el ejercicio de sus funciones.

La validación puede tener diversa intensidad en sus efectos, pero en todo caso, además de determinar la fuerza de obligar de los actos, dificulta o limita las oportunidades de invalidación de los mismos.

\section{EL TÉRMINO «VALIDACIÓN»}

«Validación» es término poco utilizado hoy en el lenguaje jurídico, aunque en él nació ${ }^{2}$. En el DRAE (sin marca de desuso o uso antiguo) tiene como primera acepción «Acción y efecto de validar», y como segunda «Firmeza, fuerza, seguridad o subsistencia de algún acto»; mientras que validar se define como «Dar fuerza o firmeza a algo, hacerlo válido». De momento, podemos entender por validación, referida a los actos jurídicos, tanto la acción de validar como el resultado de la misma, consistente en dar o aumentar la firmeza, fuerza, seguridad, subsistencia o validez de algún acto. Obsérvese la ambigüedad proceso-producto o acción-resultado tan frecuente en el lenguaje jurídico, si bien en el DRAE el énfasis se pone en el resultado o efecto (firmeza, fuerza) más que en las características de la acción (indicada con el poco expresivo dar).

Más allá del DRAE, validación parece tener hoy, preferentemente, el sentido de verificar o comprobar la adecuación de actos, procesos o resultados a las reglas o especificaciones a las que deben atenerse (comprobando, en este sentido, su validez). Este desplazamiento semántico, del efecto a la acción (que puede comprobarse en ese riquí-

${ }^{2}$ En el Diccionario de Autoridades, 1739, se define: «Firmeza, fuerza, seguridad o subsistencia de algún acto. Lat. Validatio, Confirmatio. Ordenam. R. lib. 5. t. 2. gloss. 1. 1. Para mayor validación de dicha merced, de nuestra ciencia, sabiduría, y poder Real, etc.».

El término se ha conservado en la fórmula arcaizante y solemne con la que el Jefe del Estado ratifica los tratados internacionales firmados por el Reino de España. Por ejemplo, Instrumento de Ratificación de la Convención sobre los derechos de las personas con discapacidad, hecho en Nueva York el 13 de diciembre de 2006 (23 de noviembre de 2007, BOE, 21 de abril de 2008): «...Vengo en aprobar y ratificar cuanto en la misma se dispone, como en virtud del presente la apruebo y ratifico, prometiendo cumplirla, observarla y hacer que se cumpla y observe puntualmente en todas sus partes, a cuyo fin, para su mayor validación y firmeza, mando expedir este Instrumento de Ratificación firmado por Mí, debidamente sellado y refrendado por el infrascrito Ministro de Asuntos Exteriores y de Cooperación» (cursiva añadida). 
simo banco de datos que constituye Internet y que, supongo, tiene algo que ver con el uso de validation en inglés) es muy conveniente para el concepto de validación que me propongo delimitar y utilizar en este trabajo.

Cercano al concepto de validación se encuentra el de roboración ${ }^{3}$. Sus acepciones en el DRAE son: 1. Dar fuerza y firmeza a algo. 2. Reforzar con razones o argumentos. 3. Otorgar, confirmar, rubricar algo (ésta con la marca de «anticuado»). La primera acepción (y aun la segunda) coinciden prácticamente con el significado de validación. La tercera, anticuada, nos introduce en campos semánticos de gran interés: otorgar, confirmar, rubricar. Añado autorizar, a lo que da pie también el sentido del término «robra» ${ }^{4}$ en su segunda acepción (DRAE, con la marca de anticuado): «escritura o papel autorizado para la seguridad de las compras y ventas o de cualquier otra cosa», que nos introduce muy derechamente en asuntos centrales de nuestro tema ${ }^{5}$.

«Roboración», por tanto, sería también buen candidato como término central en estas páginas. Prefiero, sin embargo, el de validación, por compartir raíz con «validez» y ser éste el centro del campo semántico que nos interesa. También porque validación tiene fáciles equivalentes en otros idiomas, y no tanto roboración.

\section{DEFINICIONES}

Propongo las siguientes definiciones:

Def. 1: Validación. «Una norma jurídica ha sido validada = def. (1) El sujeto $P_{i}$ ha realizado el acto jurídico $A_{\imath}$ y (2) $A_{i}$ ha producido prima facie la norma jurídica $N_{j}^{t}$ y (3) el acto jurídico $V_{i}$ afirma o presupone que $A_{i}$ es válido en el sistema $S_{k}$ y (4) entonces (4.1) $N_{j}$ tiene fuerza de obligar $F o N_{j}$ a no ser que se produzca un acto de invalidación $I N_{j}$ y $(4.2)$ se restringen las posibilidades de $I N_{j} \gg$.

$V_{i}$ es el acto de validación, cuyos efectos son, conjuntamente, los señalados en 4.1 y 4.2. El acto de validación $V_{i}$ puede afirmar o presuponer sólo que $A_{i}$ observa algunos de los requisitos impuestos por las normas de $S_{k}$ (por ejemplo, sólo competencia y procedimiento, pero no coherencia con normas superiores).

La definición de validación quiere referirse tanto a normas generales (como leyes) como a normas particulares (como sentencias o contratos).

Esta definición de validación enlaza con las que ofrecí sobre validez de los actos jurídicos, en particular las de validez de un acto jurídico respecto de una norma y validez

${ }^{3}$ Que tanto «roboración» como «validación» sean palabras que el corrector de Word admite sin protesta es buen indicio de que no se ha perdido su uso en castellano.

${ }^{4}$ En su primera acepción en DRAE, robra es «Agasajo del comprador o del vendedor a quienes intervienen en una venta» (un equivalente funcional de la escritura, podemos advertir ya, dirigido a «la seguridad de las compras»).

5 Dic. de Autoridades, 1737, voz «robra»: «Escritura o papel autorizado, para la seguridad de las compras y ventas, o passage de las aduanas. Tráhele Covarr. en su Thesoro. Lat. Syngraphum publicum. Litera publica»; y «robrar», «Hacer la escritura o papel autorizado, que llaman Robra. Tráhele Covarr. en su Thesoro en la voz Robra. Lat. Literas, vel tabulas publicas conficere, signare». En efecto, en el Tesoro de Covarrubias se lee: «robra. La escritura que se hace de alguna compra o venta, a roborando, porque se confirma con la escritura. Robrar, hacer la tal escritura». 
de un acto jurídico en el sistema (DELGADo ECHEVERRía, 2005). Estaban, a su vez, inspiradas en definiciones de VON WRIGHT, 1963: pp. 201-205, y ALCHOURRÓN y BULYGIN, 1971: p. 120, y 1979, p. 73, sobre validez de normas. Conviene recordarlas aquí.

Def. 2: «Un acto $A_{i}$ es válido respecto a una norma $N_{j}=\mathrm{df}$. (1) $N_{j}$ confiere poder un sujeto $P_{i}$ para realizar el acto jurídico $A_{\imath}$ y (2) y el sujeto $P_{i}$ ha realizado el acto jurí$\operatorname{dico} A_{\imath}$.

Def. 3: «Un acto $A_{i}$ es válido en el sistema $S_{k}=d f$. En el sistema $S_{k}$ hay por lo menos una norma $N_{j}$ tal que $A_{i}$ es válido respecto a $N_{j}$.

Para completar la definición de validación, se precisa la de invalidación.

Def. 4: Invalidación. «Una norma ha sido invalidada = def. (1) El sujeto $P_{i}$ ha realizado el acto normativo $A_{i}$ y (2) $A_{i}$ ha producido prima facie la norma jurídica $N_{j}$ y (3) el acto jurídico $I N_{j}$ afirma que $A_{i}$ es inválido conforme a una norma del sistema $S_{k}$ o que no es válido conforme a ninguna norma del sistema $S_{k}$ y $(4) N_{j}$ carece de fuerza de obligar FoN $\gg$.

Obviamente, validación e invalidación no son conceptos que puedan definirse el uno por el otro.

Y para aclarar por comparación la definición de validación, es útil una definición de convalidación.

Def. 5: Convalidación. «Una norma ha sido convalidada $=$ def. (1) El sujeto $P_{i}$ ha realizado el acto normativo $A_{i}$ y (2) $A_{i}$ ha producido prima facie la norma jurídica $N_{j}$ y (3) el acto jurídico $C N_{j}$ afirma que $A_{i}$ es válido en el sistema $S_{k}$ y (4) entonces (4.1) $N_{j}$ tiene fuerza de obligar $F o N_{j}$ y (4.2) se excluye la posibilidad de $I N_{j} \gg$.

Ni def. 1 ni def. 5 presuponen la corrección de $A_{i}$ respecto de todas las normas de $S_{k}$ (tampoco la incorrección). El caso paradigmático de convalidación es la «cosa juzgada»: la sentencia definitiva del órgano que tiene la última palabra impide cuestionar en adelante la validez de la norma en el sistema, que definitivamente tendría (convalidación) o no (invalidación) fuerza de obligar. Mientras que en los casos de validación, la validez de la norma pude todavía ser discutida con consecuencias en el sistema, pero ahora con restricciones.

\section{EL CONCEPTO DE VALIDACIÓN EN LA TEORÍA DE LA NORMA}

La lectura de las páginas que KELSEN dedicó al conflicto entre normas de diverso nivel (leyes «inconstitucionales», sentencias «contrarias a la ley») sigue produciendo desasosiego. KELSEN presenta problemas de muy difícil solución y la que él da (la llamada cláusula alternativa tácita) es insatisfactoria y sorprendente. Parece una contradicción que destruye en sus raíces la concepción del Derecho como sistema escalonado de normas afirmar que cuando una norma superior faculta para producir normas con arreglo a cierto procedimiento y con determinado contenido, faculta también alternativamente para producirlas sin atender a ese procedimiento o dotándolas de otro contenido. Mantener que en ambos casos la norma inferior es igualmente válida parece un contrasentido, aunque se añada que ambas opciones no son iguales y que «la cons- 
titución, si bien no puede excluir el segundo camino, da preeminencia al primero» y que las personas que han intervenido en las producción de la norma «por el segundo camino» pueden incurrir en responsabilidad (KELSEN, 1979: 280-281).

No es de este lugar la reconstrucción del pensamiento KELSENiano a este respecto, la posible evolución del mismo, las vías intentadas para explicarlo y, sobre todo, para criticarlo e intentar superarlo. Para situar en la teoría de la norma el concepto de validación cortaré de un tajo el nudo gordiano que KELSEN ata con el concepto de validez (Geltung) ${ }^{6}$ : distinguiré, de una parte, la validez como corrección en la producción de la norma con arreglo a la norma de competencia y, de otra, la validez como fuerza de obligar. Dos conceptos con extensión referencial distinta. Una distinción, por lo demás, ampliamente asumida por los autores, con terminología algo variable que indica también disensiones parciales subyacentes: a la concurrencia de todos los requisitos (competencia, procedimiento, materia y contenido) suele llamarse validez; la fuerza de obligar se designa como existencia, vigencia, obligatoriedad, eficacia, aplicabilidad. Opto por fuerza de obligar, o fuerza obligatoria, porque me parece más adecuado para referirlo tanto a las normas generales (leyes) como a la individuales (sentencias, contratos), y porque pone de relieve que el sentido del ordenamiento es que estas normas deben ser obedecidas (que es legítimo obedecerlas y legítimo exigir obediencia) aunque haya en la sociedad diversidad de opiniones sobre si la norma es válida (es decir, sobre si se ha producido correctamente), mientras una decisión revestida de autoridad no la invalide.

En este contexto, un acto de validación tiene como consecuencia constituir la fuerza de obligar de la norma de manera provisional. Un acto validado puede o no haber sido correctamente producido de acuerdo con la norma que regula su producción, incluida la no contradicción con normas superiores: esto es algo sobre lo que caben diversas opiniones (por sí irrelevantes en el sistema); pero la norma que es el sentido objetivo del acto validado tiene en todo caso fuerza de obligar, mientras no sea invalidado por el órgano competente mediante el procedimiento adecuado.

\section{LA PUBLICACIÓN DE LAS NORMAS GENERALES}

Cuál sea el acto de validación que constituye provisionalmente la fuerza de obligar de una ley es cuestión que depende de cada ordenamiento estatal. Son candidatos posibles, al menos, los actos de sanción, de promulgación y de publicación (uno o varios de ellos, en relaciones variables). No discutiré aquí la cuestión en general y me limito a algunas observaciones.

Los autores suelen considerar la sanción, la promulgación y la publicación, sin mucho compromiso, como requisitos de eficacia (o acaso también de validez $)^{7}$. Lo que yo

\footnotetext{
${ }^{6}$ Sobre el uso de Geltung por los filósofos del Derecho en lengua alemana y, en particular, por KeLSEN, véase DELGADO PINTO, 1990: 101-103, en particular nota 1; específicamente, sobre la traducción al castellano de Geltung en KelSEN, para la que propone «vigencia», p. 107, n. 2. Otras observaciones en DeLGAdo ECHEVERRÍA, 2003: pp. 233-235. p. 321.

7 Cfr. GUASTINI, 1999, sobre promulgación, pp. 320 y 367; sobre publicación como condición de eficacia,
} 
añado es que pueden ser también, y al menos uno de ellos es, acto de validación: en el Derecho español, cabe dudar si la sanción-promulgación (sólo promulgación en las leyes autonómicas) o la publicación. El principio de seguridad jurídica y la exigencia constitucional de publicidad de las leyes me inclinan a considerar, en todo caso, la publicación como acto de validación, necesario para la Fo de la ley. Los ciudadanos sólo podemos comprobar la publicación en el Boletín Oficial; ni siquiera sabemos dónde están ni si se puede acceder a los documentos de sanción-promulgación firmados por el rey y refrendados por el presidente de gobierno (o los de promulgación firmados por los Presidentes autonómicos); de hecho ni siquiera suele publicarse su texto en los repertorios que reproducen las leyes ${ }^{8}$. Pero no habría dificultad en admitir que actos de validación son tanto el de promulgación como el posterior de publicación, que constituirían un proceso de validación, en el que el último acto (publicación) ha de incluir referencia a los anteriores.

Me parece útil distinguir tres posibles funciones distintas de la publicación: signo de la existencia de una norma, requisito de validez de la norma, acto de validación. Las tres funciones pueden coexistir en un ordenamiento, con relaciones variables entre ellas.

a) La publicación como signo de existencia de la norma. Signo entre otros, como podrían ser noticias en la prensa o comentarios escuchados a personas con autoridad social, por los que el ciudadano puede guiarse - a su riesgo — para conocer las normas que pretenden su obediencia.

b) La publicación como requisito de validez. Así es en el Derecho español. Las normas generales no publicadas no tienen fuerza de obligar, por lo que la publicación ha de entenderse como el último acto del procedimiento establecido para dictar normas generales. La distinción, aquí, entre requisitos de validez y requisitos de eficacia, para introducir en los segundos la publicación, no me parece útil y, en todo caso, creo que no altera el análisis que estamos conduciendo. Que la publicación sea requisito de validez (o de eficacia) asegura que carece de fuerza de obligar la norma no publicada, pero por sí no dota de esta fuerza a la publicada.

c) Publicación como validación. La publicación no es un mero hecho, sino un acto de autoridad que ordena la publicación, precedido en nuestro derecho, para las leyes,

${ }^{8}$ Las fórmulas actuales de sanción y promulgación de las leyes españolas son las siguientes, tomadas de la Ley 54/2007, de 28 de diciembre, de adopción internacional (BOE 29 de diciembre de 2007: como se dice en el texto, es raro que estas fórmulas se transcriban en los repertorios usuales).

(Al principio). «Juan Carlos I / Rey de España / A todos los que la presente vieren y entendieren / Sabed: Que las Cortes Generales han aprobado y Yo vengo en sancionar la siguiente ley».

(Al final). «Por tanto, / Mando a todos los españoles, particulares y autoridades, que guarden y hagan guardar esta ley./ Madrid, 28 de diciembre de 2007. / Juan Carlos R. / El Presidente del Gobierno, / José Luis Rodríguez Zapatero».

Ejemplo de promulgación y orden de publicación de una ley autonómica [Ley 13/2006, de 27 de diciembre, de Derecho de la Persona (Aragón)]. «En nombre del Rey y como Presidente de la Comunidad Autónoma de Aragón, promulgo la presente Ley, aprobada por las Cortes de Aragón y ordeno se publique en el Boletín Oficial de Aragón y en el Boletín Oficial del Estado, todo ello de conformidad con lo dispuesto en el art. 20.1 del Estatuto de Autonomía».

A los efectos de este trabajo, es indiferente el ámbito del juicio de conformidad con el ordenamiento que el Jefe del Estado o el Presidente de un gobierno autonómico han de hacer sobre el documento legislativo que sancionan, promulgan u ordenan publicar: el mínimo, que el documento ha llegado a sus manos por el cauce adecuado y con las firmas necesarias. Es muy distinta e interesante, en cuanto que reconoce al Presidente de la República poderes aparentemente discrecionales, aunque limitados, la regulación italiana (arts. 73 y 74 de la Constitución italiana). 
por las necesarias sanción y promulgación (o sólo promulgación en las leyes autonómicas). Son actos de autoridades del poder ejecutivo (la sanción, del rey, con refrendo). Escribe KELSEN: «El órgano constitucional competente para efectuar la publicación (...) debe por lo menos poder examinar si aquello que se presenta subjetivamente como ley, ha sido en general dictado por el órgano llamado por la constitución a legislar, aun cuando el órgano con competencia para efectuar aquel limitado examen no pueda examinar el procedimiento en que la ley fue dictada, o si el contenido de la decisión es conforme a la constitución; no puede estar obligado a publicar como ley (...) todo aquello que se presenta como ley» (KELSEN, 1979: 279). El ámbito más o menos amplio de las facultades de comprobación de la regularidad de la formación de la ley es contingente y depende de cada ordenamiento, pero si existen estos órganos específicos con autoridad para promulgar y publicar las leyes, han de poder comprobar al menos que los enunciados normativos que publican son imputables al órgano legislativo constitucionalmente establecido. Además, el acto de publicación debe ir precedido de la comprobación del acto de sanción-promulgación.

Creo que, en el Derecho español, la publicación de las leyes no es sólo un requisito de validez, sino también un acto de validación que, como tal, constituye el deber de obedecer la ley publicada (mientras la ley no sea, eventualmente, invalidada). Es lo que resulta de la Constitución, al establecer el principio de publicidad de las leyes (como parte del principio de seguridad jurídica), pero también al establecer el recurso de inconstitucionalidad, con sus precisiones de legitimación y plazos y la previsión de poder o no decretar el Tribunal la suspensión de la entrada en vigor de la ley impugnada.

Creo que sería oportuno que la doctrina especializada realizara un análisis más profundo de los actos de sanción, promulgación y publicación de las leyes (y las garantías de que están revestidos) en nuestro Derecho y, probablemente, en otros de nuestro entorno. Tengo la sensación de que se tratan con cierta ligereza como meros «formulismos» y la publicación como un mero hecho del que se desconoce el responsable de ordenarla. Pienso también que merecerían estos actos una regulación legal más precisa. Para ambas tareas, dogmática y normativa, el concepto de «validación» espero que resulte de utilidad.

\section{VALIDACIÓN DE OTRAS NORMAS}

Signos que permiten la recognoscibilidad de las normas, requisitos de validez y actos de validación se presentan respecto de todas las normas, generales o individuales, si bien con arreglos que pueden ser distintos de caso a caso. Todas las normas generales de rango inferior a las leyes requieren de su publicación como requisito de validez, y la publicación es simultáneamente acto de validación (basado a su vez en una certificación emitida por el funcionario competente, fedatario público). Las sentencias se hacen públicas en la sala del tribunal mediante certificación del secretario del tribunal y sólo entonces vinculan a las partes. Los contratos, en el Derecho español, no requieren habitualmente ninguna forma ni formalidad para su validez, sino que la eventual intervención notarial, o su toma de razón en determinados registros, constituye una validación. 
En cada uno de estos casos (hay otros muchos) la validación afirma o presupone más o menos requisitos de validez del acto normativo validado. Hay un mínimo: la autoría del acto, es decir, que aquellos enunciados normativos proceden de quien dicen proceder, y que este autor está habilitado para emitir actos de este tipo. Puede incluir también la observancia del procedimiento. En la validación de los actos de los particulares, es habitual que las normas prevean también una comprobación del contenido de los actos y de su coherencia con normas superiores («legalidad»).

Hay, por tanto, una importante diferencia entre la validación de los actos de autoridades públicas y los actos de los particulares. Los primeros son validados de ordinario sin más comprobación que la de la validez formal, y aun ésta no siempre plenamente. Los segundos son objeto de comprobación también en su validez material. Lo que significa que los primeros tienen fuerza de obligar siempre que sean identificados como actos de la autoridad competente; mientras que los actos de los particulares han de pasar filtros más exigentes. Ya se comprende que el sistema ha de suponer fácilmente que los actos de las autoridades cumplen todos los requisitos de validez —entre otras razones, porque es obligatorio que los cumplan- mientras que los actos de los particulares han de ser comprobados más intensamente por alguna autoridad. Además - pensando ahora en las consecuencias de la validación-, las posibilidades de invalidación son mucho más limitadas para los actos de las autoridades que para los de los particulares. Una ley publicada sólo puede perder su fuerza de obligar mediante sentencia del Tribunal Constitucional (que sólo cabe pronunciar previa interposición de recurso con legitimación políticamente limitada y plazo de caducidad, o bien a consecuencia de cuestión planteada por los jueces cuando y como esto es posible); las normas reglamentarias son susceptibles de impugnación por ilegalidad de manera general durante cierto plazo, o bien en relación con cada acto de aplicación singular, ante la jurisdicción ordinaria; las sentencias sólo son susceptibles de los recursos previstos en cada caso; mientras que la validez de los contratos o de los testamentos podrá ser revisada por los tribunales en todos los casos en que se les requiera una decisión fundada en estos actos, y la validación notarial no excluye tampoco que otras autoridades puedan negar la fuerza de obligar del acto en el ámbito de su competencia.

\section{LAS NORMAS DE VALIDACIÓN}

Las normas de validación proceden de momentos históricos diferentes y se presentan por separado en diversos conjuntos normativos. La Constitución se ocupa de la sanción, promulgación y publicación de las leyes (normas completadas por otras de menor rango y, sobre todo, por convenciones y costumbres constitucionales); las leyes orgánicas del poder judicial y de enjuiciamiento contienen normas sobre la intervención de los secretarios judiciales; la LRJAP establece la «presunción de validez» de los actos de la administración sometidos al Derecho administrativo; para los actos de los particulares, las leyes del notariados e hipotecaria regulan los principales actos de validación de los notarios y de los registradores de la propiedad. Pero no es la interpretación y explicación de estas normas el objeto de este trabajo, sino señalar los rasgos comunes de todas las normas de validación, según el concepto que proponemos. ¿Qué tipo de normas son? 
Para responder a esta pregunta seguiremos fundamentalmente a H. L. A. HART. HART no menciona en ningún momento las normas de validación, aunque sí hace algunas referencias que podemos aprovechar a nuestro propósito. En el capítulo V de su obra fundamental (dedicado a «El derecho como unión de reglas primarias y secundarias») se ocupa (1961: 119) de la «conexión muy estrecha» que habrá «entre las reglas de cambio y las de reconocimiento: porque donde existen las primeras, las últimas necesariamente incorporarán una referencia a la legislación como característica obligatoria de las reglas, aunque no es menester que mencionen todos los detalles del procedimiento legislativo. Por lo común, las reglas de reconocimiento considerarán que un certificado oficial, o una copia oficial, bastan para acreditar que se ba cumplido con el procedimiento establecido (en el original, quizás con mayor fuerza, se dice «a sufficient proof of due enactement»). La regla de reconocimiento, por tanto, no exige (comprobación de) la (plena) validez de la norma producida según las normas de cambio, sino sólo un «certificado oficial» ${ }^{9}$. Pero es obvio que la norma de reconocimiento que se conforma con un certificado o copia oficiales no es la dirigida a las autoridades que tienen la última palabra, las cuales han de poder enjuiciar plenamente la validez de la ley (salvo que aquel legislador sea la autoridad que tiene la última palabra). De donde resulta que en la compleja regla (o principio) de reconocimiento (o en la pluralidad organizada de reglas de reconocimiento) hay una regla de reconocimiento prima facie que presupone otra regla, es decir, una regla de atribución de poderes que los confiere a una autoridad para «certificar» la existencia de la norma. Es esta conjunción de regla de reconocimiento y regla que atribuye poderes la que constituye la regla de validación.

Las reglas de validación son reglas de reconocimiento subordinadas (en el sentido de HART, 1963: 126), en cuanto que sus consecuencias pueden ser suprimidas mediante actos (de invalidación) cuya validez deriva de la regla de reconocimiento última. Quizás pueden considerarse «reglas de reconocimiento derivadas» en el sentido —o sentidos- que explica RuIZ MANERO (1990: 124).

Son reglas contingentes, si bien exigidas en los complejos ordenamientos contemporáneos por el principio de seguridad jurídica. Las hay en ordenamientos muy anteriores: escribas, secretarios y cancillerías no son de hoy, y respecto de los actos de los particulares, son probablemente coetáneas a las reglas de adjudicación y en íntima conexión con estas. Respecto de las leyes, adquieren mayor importancia y especiales perfiles cuando las constituciones sujetan los actos normativos del legislador a exigencias en cuanto al contenido, es decir, cuando se plantea el problema de la validez (existencia, fuerza de obligar) de las leyes inconstitucionales.

El poder para validar está conferido a sujetos muy distintos, en elencos más o menos relacionados con el tipo de actos normativos. Si éstos proceden de autoridad pública, sólo la misma u otra autoridad pública podrán validar. Las autoridades judiciales, que tienen «la última palabra revestida de autoridad» tienen también muchas veces «la penúltima palabra», es decir, dictan resoluciones que, antes de ser firmes, no con-

\footnotetext{
9 Véase también, p. 40, en un contexto menos claro, la referencia a un certificado: «A veces las normas acuerdan valor definitivo, en lo que hace al procedimiento interno, a un certificado en que conste que los procedimientos exigidos han sido observados».
} 
validan definitivamente la norma, sino que la validan a reserva de los posibles recursos o, si la resolución se ha tomado en procesos sin efecto de cosa juzgada, de posibles procesos «plenarios» posteriores.

La validación por el propio sujeto o sujetos autores de la norma (autovalidación) se manifiesta sobre todos respecto de los actos de los particulares, pero es pensable (si bien hoy no parece muy extendido) en las autoridades públicas: por ejemplo, la pronunciación de una fórmula o la colocación de un sello por el mismo autor del acto. En cambio, los actos de los particulares pueden ser validados también mediante formas o formalidades que no requieren intervención de autoridades (fórmulas verbales, sellos, testigos, apretón de manos, lifara o banquete ritual, arras, escritura, juramento, formularios tales como los de la letra de cambio o el cheque), si bien los efectos en cada caso pueden ser muy diferentes y discutibles y conviene tratarlos por separado de los supuestos de intervención de autoridad pública, que son únicos comprendidos en nuestra definición de validación.

\section{LAS NORMAS VALIDADAS}

Las normas validadas son un subconjunto de normas que no coincide exactamente ni con el de las normas (plenamente) válidas ni con el de las normas con fuerza de obligar. En cuanto a esto último, la coincidencia será completa si la validación es, al mismo tiempo, requisito de validez (como la publicación lo es para las leyes), y el ámbito de no coincidencia será mayor en los actos de los particulares cuando se admite que estos pueden ser plenamente válidos sin sujetarse a ninguna forma pública, es decir, cuando no es requisito de validez la forma y pueden valer «por el mero consentimiento» (como dice, de los contratos, el art. 1.258 CC español).

Las normas validadas no son un subconjunto de las normas (plenamente) válidas, pues pueden o no reunir todos los requisitos de validez (incluidos los materiales o de contenido). A este respecto, ocurre lo mismo que con el conjunto de las normas convalidadas, es decir, aquellas declaradas válidas por las autoridades que han pronunciado al respecto la última palabra revestida de autoridad. La clase de las normas convalidadas no contiene sólo normas válidas y por la misma razón («el órgano de control de la validez no es infalible») la clase de las normas inválidas puede contener normas convalidadas (GUASTINI, 1999: 359, 369, 411, n. 67). La convalidación no produce la certeza respecto de la validez del acto, ni la presupone (tampoco presupone la invalidez) sino que pone fin al debate con efectos jurídicos sobre la validez. Podrá continuar en la sociedad y en la dogmática jurídica un debate sobre si el acto normativo cumplió todos los requisitos de la norma que regulaba su producción (incluida su compatibilidad con normas superiores), pero ahora es seguro en el sistema que la norma tiene y tuvo fuerza de obligar. El acto de convalidación — como el de validación — afirma o presupone que el acto se formó correctamente, pero constituye validez (fuerza de obligar) con independencia de la corrección de la afirmación o presuposición ${ }^{10}$. En particular,

${ }^{10}$ En realidad hay un continuum entre validación y convalidación. Algunos actos de validación pueden producir efectos preclusivos muy fuertes, mientras que el supuesto de convalidación en el que se piensa, que es la sentencia (con efecto de cosa juzgada) que rechaza una acción o recurso dirigido a anular una norma, no siem- 
la «cosa juzgada» que convalida la norma pone fin al debate sobre la validez por razones de seguridad jurídica, razones que pueden considerarse «principios institucionales» de cualquier sistema jurídico (en el sentido de ATIENZA y RuIZ MANERO, 2001); también por razones de seguridad jurídica y de eficacia del Derecho la validación restringe las posibilidades del debate jurídico, constituyendo validez (fuerza de obligar) mientras una autoridad competente no invalide el acto. Esta autoridad competente puede ser la misma que lo sería para convalidar.

Mientras que las normas convalidadas y las invalidadas se encuentran en una situación definitiva (pues su estatus no puede ser ya debatido dentro del sistema), las validadas tienen una situación provisional. Provisional, aquí, no significa sino que es posible todavía un juicio sobre la validez (y contrario a la misma) con consecuencias en el sistema. En el mayor número de casos este juicio no se producirá y cabe entender que ésta -es decir, evitar o restringir las posibilidades de un juicio posterior- es una de las finalidades de la validación.

\section{MUNDOS JURÍDICOS ÓPTIMOS}

Al final de su trabajo «sobre normas inconstitucionales», tras presentar la distinción entre validez y vigencia, J. J. Moreso introduce la noción de «Mundos jurídicos óptimos» (MJO). «Llamaré mundo jurídico óptimo (MJO) a aquel mundo posible en el cual todas las autoridades que crean normas (con apariencia de normas jurídicas) lo hacen en virtud de una norma previa que les autoriza a ello». «Un mundo en que todos los actos de creación de leyes vigentes son actos válidos (en el sentido de que existe una norma válida que los autoriza)» (1993: 104-105).

En un mundo jurídico óptimo tendrían fuerza de obligar todas y solas las normas producidas cumpliendo plenamente las exigencias de las normas que regulan su producción. Un MJO no incluiría las normas validadas o convalidadas que no cumplieran ese requisito e incluiría, por el contrario, las invalidadas «indebidamente». «MJO es, claramente, un mundo ideal».

En un MJO los sujetos sabrían con seguridad cuáles son las normas válidas: por hipótesis (en este mundo contrafáctico), todas las vigentes. En un MJO son innecesarios los pronunciamientos de las autoridades que tienen la última palabra revestida de autoridad: «En MJO no hacen falta mecanismos como el control de constitucionalidad o la apelación de sentencias» (MORESO, 1993: 105). Pero el mundo jurídico real (MJR) es un mundo jurídico defectuoso (MJD), en el que las autoridades y los particulares, intencionadamente o por ignorancia o negligencia, producen actos normati-

pre impide absolutamente que con posterioridad se vuelva a juzgar sobre la validez de la misma, bien con fundamento en otros vicios de invalidez bien a instancia de otros legitimados. La cosa juzgada tiene sus límites personales y materiales. En este sentido, decisiones judiciales que consideraríamos en principio casos de convalidación pueden verse también como ejemplos de validación «fuerte» (con gran limitación de las posibilidades de nuevo enjuiciamiento de la validez). Obsérvese también que invalidación y convalidación no son fenómenos simétricos: la sentencia que invalida expulsa definitivamente la norma del sistema, sin posibilidad de posterior reconsideración; mientras que la sentencia que rechaza la demanda de invalidez no por ello declara necesariamente la validez ni precluye totalmente que se cuestione con posterioridad. 
vos incorrectos. En el MJR no está a nuestro alcance el saber con seguridad cuáles son esas normas que, todas y sólo ellas, constituirían el sistema de normas válidas. Para el objetivo de conocer si una norma ha sido correctamente formada cumpliendo todos los requisitos de validez, es insuficiente el remedio de acudir a las autoridades que tienen la última palabra revestida de autoridad: su criterio será más o menos fiable, y la argumentación en que fundamentan su juicio más o menos convincente, pero siempre pueden equivocarse o engañarnos ${ }^{11}$. Las autoridades no son infalibles ni necesariamente honestas.

KELSEN insiste en que la pregunta sobre la validez de las normas —en particular, en razón de sus relaciones con normas superiores - no puede plantearse con independencia de la cuestión sobre quién ha de responder la pregunta anterior ${ }^{12}$. No cualquier sujeto, responde: «Si la constitución autoriza a cualquiera a resolver este interrogante, apenas si podría contarse con leyes obligatorias para los sujetos y órganos de Derecho. Si es menester impedir tal situación, la constitución sólo puede autorizar a un determinado órgano en este respecto» (1979: 278). Difícil disentir de esta opinión. En general, la constitución y las leyes predeterminan los órganos que, con competencia exclusiva, se pronuncian sobre la validez de los actos normativos de autoridades y particulares. Pero sus pronunciamientos son decisivos, no porque declaran que el acto normativo se ha formado correctamente (juicio «de expertos» que puede tener mayor o menor fuerza de convicción), sino porque lo que hacen es constituir la fuerza de obligar: su pronunciamiento es definitivo, pero no infalible. En palabras de MORESO (1993: 108-109), generalizables a los pronunciamientos de todos los tribunales sobre cualesquiera normas, «las sentencias de un Tribunal Constitucional tienen valor declarativo en lo que respecta a la validez de las normas, pero tienen valor constitutivo en lo que respecta a su vigor...».

En el MJR es imprescindible esta posibilidad de someter a las normas (públicas y privadas) a un juicio de invalidación/convalidación del que resulten decisiones constitutivas sobre la fuerza obligatoria de las normas. Pero no es suficiente para la seguridad jurídica. Es preciso también saber a qué atenernos respecto de las normas (que aparecen como tales) sin necesidad de procesos de invalidación/convalidación o antes de que se inicien y concluyan. Necesitamos saber a qué atenernos sobre las reglas que debemos obedecer o con arreglo a las cuales ejercemos nuestros derechos y que han de ser aplicadas por las autoridades. El MJR es un MJD, en el que tienen fuerza de obligar normas no producidas válidamente (y del que son excluidas indebidamente normas válidas). Pero el MJR será menos defectuoso si hay criterios establecidos, generales y previos a los pronunciamientos definitivos sobre la validez (siempre posibles, pero poco frecuentes), que indiquen con la mayor claridad las normas obligatorias para cada uno: este criterio nos lo proporcionan los actos de validación. La validez (corrección) necesita de la validación (y no sólo de la convalidación) como condición de posibilidad en la práctica social del Derecho.

${ }^{11}$ Cabe el «riesgo de error honesto, abuso o violación», y «es imposible proveer mediante reglas a la corrección a las infracciones de todas las reglas» (HART, 178).

12 «La pregunta referente a si una norma producida por un órgano jurídico corresponde a la norma superior que determina la forma de su producción o también su contenido, no puede separarse de la pregunta sobre quién está facultado por el orden jurídico para resolver la pregunta previa» (1979: 274). 


\section{PRESUNCIÓN DE VALIDEZ Y VALIDACIÓN}

Cabe abordar el indicado problema de seguridad jurídica suponiendo o introduciendo una «presunción de validez» de las normas. Entre presunción de validez y validación hay sin duda implicaciones relevantes, por lo que parece útil hacer algunas consideraciones sobre las presunciones de validez. Adelanto ya que el análisis que de ellas ofrecen los autores me parece insuficiente y que uno de sus puntos débiles es precisamente la fijación del hecho a partir del cual se presume la validez (¿existencia?, ¿resultado institucional?, ¿corrección en cuanto a sujeto y materia?).

Suele hablarse de presunción de constitucionalidad de las leyes, así como de presunción de legalidad o de validez de los reglamentos y de los actos administrativos. En ocasiones, las leyes formulan explícitamente presunciones de validez ( $v . g r$. de los actos administrativos). Algunos autores se han planteado también la presunción de validez de los actos (contratos) de los particulares, como una manifestación del favor negotii (de favor matrimonii en la presunción de validez del mismo) ${ }^{13}$.

Creo que no se ha formulado una presunción de validez de las sentencias, pero sí, como se sabe, una «presunción de cosa juzgada», que sería una presunción de validez en su forma más fuerte: iuris et de iure. Paralelamente, cabría hablar de presunción de validez (iuris tantum) de todas las resoluciones judiciales, incluidas las no firmes o no definitivas. Pero las mismas razones por las que se niega que la cosa juzgada se explique adecuadamente como una presunción deberían llevar a negar este carácter a toda «presunción de validez». La sentencia firme y definitiva produce sus efectos con independencia de que el tribunal haya acertado o no al aplicar las normas y, en su caso, a declararlas válidas o inválidas; en este sentido la sentencia tiene eficacia constitutiva. Podrá decirse que la norma que atribuye este poder al juez está basada en que es razonable, o que es preferible, presumir que el juez acierta, pero no es una norma de presunción, sino de atribución de poder. Del mismo modo, las normas de validación atribuyen a una autoridad el poder de constituir provisionalmente fuerza de obligar (de la norma validada), mientras no sea invalidada, en su caso, por el órgano y mediante el procedimiento adecuado, con independencia de que la autoridad validante acierte o no en su juicio sobre la validez de la norma.

Parece útil, en todo caso, tratar de precisar en qué puede consistir una presunción de validez de normas o de actos, para compararla y relacionarla con una norma de validación.

D. MENDONCA (1998) nos presenta la propuesta de UlLMANN-MARGALIT, según la cual las presunciones pueden representarse mediante una fórmula con la siguiente forma estándar:

(1) Pres $(P, Q)$,

donde «Pres» representa el operador de presunción, «P» el hecho que da lugar a la presunción y «Q» el hecho presumido. La fórmula se leería: «P da lugar a la presunción de que $Q »$, o «Existe la presunción, a partir de $\mathrm{P}$, que $Q »$.

${ }^{13}$ Un amplio e incisivo tratamiento general de la presunción de validez, desde el Derecho administrativo español, nos ofrece M. REBOllo Puig, 2005. Creo que la distinción que introduce entre presunción de legalidad y presunción de validez coincide aproximadamente con la distinción que sigue en el texto según se interprete $(Q)$ como corrección o como fuerza de obligar. 
Esta fórmula corresponde sin duda a intuiciones muy extendidas sobre qué sea una presunción. Hagamos un primer intento de interpretar la fórmula para una presunción de validez. ¿Qué significarían $P$ y $Q$ ? El hecho que da lugar a la presunción podría ser la «existencia» de la norma, o su «validez formal» (también un acto que constata su existencia, lo que acercaría la presunción de validez a una norma de validación). Evidentemente, $P$ no puede ser el hecho de que la producción de la norma haya sido plenamente regular en forma y fondo ${ }^{14}$. Que $P$ sea alguna de estas cosas (u otras que ahora no imagino) dependerá de la configuración específica de la presunción en el sistema de referencia.

En cuanto a $Q$ la expresión «presunción de validez» interpretaría $Q$ como «validez». Pero ¿en qué sentido de validez? Puede ser, al menos:

a) Validez como adecuación plena (competencia, procedimiento, materia y contenido) a las normas que regulan su producción.

b) Validez como fuerza de obligar.

A) Consideremos, en primer lugar, la alternativa a). De este modo, y tomado para $P$ el significado de «existencia», la presunción de validez tendría la siguiente forma:

(2) «Existe la presunción, a partir de que $N$ existe, que $N$ se adecua plenamente al ordenamiento».

Exploremos ahora las características de esta presunción. Siguiendo las consideraciones de MENDONCA sobre la fórmula propuesta por ULLMANN-MARGALIT, «la regla no tiene tanto que ver con la afirmación de hechos como con el proceder sobre su base» (1998: 84), es decir, que el destinatario de la presunción tome $Q$ «como si fuese verdadera, como base para actuar». En nuestro caso, que se comporte conforme al contenido de $N$ si $N$ fuera una norma válida, plenamente adecuada al ordenamiento.

MENDONCA parece suponer que las presunciones están dirigidas a los jueces ${ }^{15}$, es decir, que operan únicamente en el proceso; pero en nuestro caso tenemos que considerar destinatarios a todos los sujetos, pues las presunciones de validez operan en el tráfico jurídico y no operan, o lo hacen de otro modo, precisamente para los jueces llamados a formular juicios de validez revestidos de autoridad. Las autoridades en general (también las autoras de $N$ ), lo mismo que los particulares, han de comportarse como si $N$ fuera plenamente válida: deben cumplir los deberes establecidos en ella, pueden exigir cumplimiento a otros y deben justificar sus decisiones contando con $N$.

«Las presunciones están asociadas con ciertas inferencias, pero las presunciones, en sí mismas, no versan acerca de inferencias». Las presunciones legales de validez pueden estar basadas en la creencia de que en la mayor parte de los casos los actos de las autoridades reúnen todos los requisitos de validez formal y material, pero no establecen una inferencia en este sentido. Cabe que esta consideración probabilística (quod

${ }^{14}$ La proposición que dijera que «existe la presunción, a partir de que la norma se ha producido con total regularidad, que la norma es válida» no sería una presunción, sino una definición de validez.

${ }_{15}$ Es también el caso del importante trabajo sobre presunciones de J. AguiLó, 2006, si bien parte de su análisis podría generalizarse. La introducción de reglas legales sobre presunciones en la Ley de Enjuiciamiento Civil de 2000, en relación con la prueba de los hechos en el juicio (con la correlativa derogación de las hasta entonces presentes en el Código Civil) contribuye a olvidar el análisis de las normas de presunción que no tienen como ámbito operativo el proceso. 
plerumque accidit) sea la justificación de las presunciones legales (es más/menos frecuente $Q$ que No- $Q$, en caso de $P$ ), pero caben al menos otros dos tipos de consideraciones (MENDONCA, 95): evaluativas (las consecuencias de presumir $Q$, en caso de $P$, serían más/menos graves que las consecuencias de presumir No- $Q$, en caso de $P$ ) y procesales (es más/menos fácil producir prueba a favor de $Q$ que de No- $Q$, en caso de $P)$. Para las presunciones legales de validez, la consideración probabilística es plausible, pues podemos suponer que es lo que ocurre en la inmensa mayor parte de los casos (además, el ordenamiento toma abundantes precauciones para que así sea, en forma de cautelas organizativas, de procedimiento y sancionatorias); pero es la consideración evaluativa la decisiva: las consecuencias de presumir No- $Q$ serían catastróficas, pues cualquier sujeto podría negarse a cumplir o a aplicar la norma mientras no se demostrara que ésta se adecua totalmente al ordenamiento. La consideración procesal coopera en el mismo sentido, pues sin duda es mucho más fácil demostrar la falta de un requisito que no demostrar la presencia exhaustiva de todos los requisitos: probar la validez, en el sentido de adecuación total de la norma a las exigencias de forma y fondo de las normas que regulan su producción es extraordinariamente difícil.

Esto nos lleva a la consideración de qué significa la prueba en contrario en la presunción de validez. MENDONCA presenta la cuestión, en general, del siguiente modo. «Las normas presuntivas contienen una cláusula de prueba en contrario con las formas "a no ser que" o "hasta que", por lo que la fórmula debería recoger esta variable en su antecedente, con lo cual ella debería asumir una forma como la siguiente:

(3) «Si está probado $(P)$ y no está probado (No-Q) (o «hasta que se pruebe No$Q \gg)$, entonces es obligatorio presumir $(Q) »($ MENDONCA, 1998: 94).

Nuestra expresión (2) se completaría entonces del siguiente modo:

(3) «Existe la presunción, a partir de que $N$ existe, que $N$ se adecua plenamente al ordenamiento, hasta que se pruebe que $\mathrm{N}$ no se adecua plenamente al ordenamiento».

Pero la prueba de que $N$ no se adecua plenamente al ordenamiento, $a$ ) no es una prueba de hechos, y $b$ ) sólo puede producirse en determinados procedimientos judiciales.

En realidad $a$ ) no es una prueba, sino un juicio de adecuación de una norma a los parámetros de la norma que regula su producción, y $b$ ) lo que se produce en el correspondiente procedimiento judicial es una declaración con fuerza de cosa juzgada, que pone fin definitivamente al debate (jurídico) sobre la validez.

La presunción de validez quedaría destruida, no por la prueba de la no validez, sino por un pronunciamiento de invalidez revestido de autoridad.

B) Sigamos abora la alternativa $b$ ) («validez» como fuerza de obligar).

Si $P$ se interpreta como existencia, tendríamos:

(4) «Existe la presunción, a partir de la existencia de N, de que N tiene fuerza de obligar ( FoN), hasta que en el procedimiento adecuado se establezca que (no se adecua plenamente al ordenamiento y por tanto) no tiene fuerza de obligar» ${ }^{16}$.

${ }^{16}$ De modo similar entiende la presunción de validez Á. RóDENAS, 2006: «La mínima apariencia de cumplimiento de las exigencias que figuran en la ley pone en marcha todos los efectos jurídicos previstos para los 
Esta «presunción» apunta a una norma presente en los ordenamientos jurídicos que conocemos, justificada por razones institucionales ligadas a la eficacia del Derecho. Sin ella no sería posible la práctica social del Derecho, pues cualquiera podría en cualquier momento eximirse de la obediencia a las normas. Pero no es una presunción, sino una norma constitutiva, que vincula la fuerza de obligar de la norma a la «existencia» de la misma. Su talón de Aquiles reconocido está en la interpretación de «existencia» de la norma.

Para superar esta debilidad, puede formularse la presunción interpretando $P$ como específicos hechos o actos. En particular, como actos de autoridades que certifican la existencia de la norma.

Si $P$ se interpreta como acto de validación, tendríamos:

(5) «Existe la presunción, a partir de $V_{i}$, que $N_{j}$ tiene fuerza de obligar $F o N_{j}$, hasta que se declare con autoridad $\neg F_{O} N_{j}$.

Pero entonces, manteniendo la forma de presunción, la hemos vaciado de contenido. $F o N_{j}$ no es un hecho, ni la presunción indica que haya que comportarse o decidir sobre la base de un hecho «dado por cierto». En realidad, hemos formulado los efectos constitutivos de un acto de validación:

(6) «Dado $V_{i}$ (acto de validación referido a la norma $\left.N_{j}\right), N_{j}$ tiene fuerza de obligar, a nos ser que se produzca un acto de invalidación $I N_{j}{ }^{17}$.

Acto de validación que presupone la norma que confiere poderes de validación (la norma de validación).

No es mi intención explorar todas las posibilidades e instancias de presunciones de validez de actos y de normas. Mi propósito era construir el concepto de validación y mostrar su utilidad para dar cuenta de algunos problemas centrales en la teoría de las normas. Las relaciones entre validación y presunción de validez son indudables y la exposición anterior contribuye, creo, a perfilar el concepto de validación. Quizás también aporte alguna mayor claridad a la teoría de las presunciones de validez, sin duda acreedora de mayor atención teórica.

resultados normativos regulares, y sólo en virtud de un pronunciamiento expreso de un órgano revestido de autoridad para ello será posible romper esta presunción» (p. 269). Tal presunción está justificada por «una exigencia normativa»: «de acuerdo con nuestros sistemas jurídicos no sólo deben producir efectos jurídicos aquellas entidades jurídicas que se adecuan a las exigencias contenidas en las normas sobre la producción normativa, sino también aquellas otras que, pese a no adecuarse, presentan al menos una minima apariencia de adecuación» (p. 269, cursivas del original; también p. 276). La autora refiere también la presunción de validez a los actos de particulares, en términos, en mi opinión, necesitados de matización. Por otra parte, acepta la configuración de las presunciones de validez como presunciones-principio, siguiendo la sugestiva distinción de J. AguiLó, 2006.

${ }^{17}$ Ciertamente, cabría formular una presunción de validez interpretando $P$ como acto de validación y $Q$ como corrección o adecuación al ordenamiento: «Existe la presunción, a partir de que $V$ valida la norma $N$, que $N$ se adecua plenamente al ordenamiento, hasta que se pruebe que $N$ no se adecua plenamente al ordenamiento». En mi opinión, como resulta de todo lo dicho en estas páginas, no se trataría propiamente de una norma de presunción, sino de la expresión de alguna de las razones que justifican la existencia de normas de validación. 


\section{NÓMINA DE AUTORES Y OBRAS CITADAS}

Aguiló Regla, J., 2006: «Presunciones, verdad y normas procesales», Isegoría, 35, pp. 9-31 (luego en Aguiló Regla, J., 2008: Sobre Derecho y argumentación, Palma, Mallorca: Lleonard Muntaner, pp. 87-107).

Alchourrón, C., y Bulygin, E., 1971: Normative Systems, Viena-Nueva York: Springer Verlag (cit. por Introducción a la metodología de las ciencias jurídicas y sociales, 2. ${ }^{a}$ ed., Buenos Aires: Astrea, 1987).

Atienza, M., y Ruiz Manero, J., 2001: «La dimensión institucional del Derecho y la justificación jurídica», en DOXA, Cuadernos de Filosofía del Derecho, 24, pp. 115-130.

- 2003: «Seis acotaciones preliminares para una teoría de la validez jurídica», en DOXA, Cuadernos de Filosofía del Derecho, 26, pp. 719-735.

Delgado Echeverría, J., 2003: «Las normas derogadas. Vigencia, validez, aplicabilidad», en Derecho Privado y Constitución, 17, pp. 197-252.

- (2005): «El concepto de validez de los actos jurídicos de Derecho privado (Notas de teoría y dogmática)», en Anuario de Derecho Civil, LVIII, pp. 9-74.

Delgado PinTo, 1990: «Sobre la vigencia y la validez de las normas jurídicas», en DOXA, Cuadernos de Filosofía del Derecho, 7, pp. 101-103.

Guastini, R., 1999: Distinguiendo. Estudios de teoría y metateoría del derecho, Barcelona: Gedisa.

Hart, H. L. A., 1961: The Concept of Law, Oxford: Clarendon Press, 2. ${ }^{\text {a }}$ ed., 1974 [trad. cast. de la 1. a ed. (1961), por CARrió, G. R., 1963: El concepto de Derecho, Buenos Aires: Abeledo-Perrot].

KELSEN, H., 1960: Reine Rechtslebre, 2. ${ }^{a}$ y definitiva edición, revisada y ampliada, Viena (trad. del original en alemán por Vernengo, R. J., 1979: Teoría pura del Derecho, México: Universidad Nacional Autónoma de México).

MendOnCA, D., 1998: «Presunciones», en DOXA, Cuadernos de Filosofía del Derecho, 21, pp. 83-98.

Moreso Mateos, J. J., 1993: «Sobre normas inconstitucionales», Revista Española de Derecho Constitucional, 13, 38, pp. 81-115.

PeÑa Freire, A. M., 1999: «Validez y vigencia de las normas jurídicas», Anuario de Filosofía del Derecho, XVI, pp. 99-119.

Rebollo Puig, M., 2005: «La presunción de validez», en Civitas, Revista Española de Derecho Administrativo, 128, pp. 587-638.

RÓDENAS, Á., 2006: «Sobre la validez jurídica: entre la normatividad y la convención», Analisi e diritto 2006 (a cura di P. COMANDUCCI e R. GUASTINI), pp. 255-276.

Ruiz MANero, J., 1990: Jurisdicción y normas. Dos estudios sobre función jurisdiccional y teoría del derecho, Madrid: Centro de Estudios Constitucionales.

Von Wright, G. H., 1963: Norm and Action, A Logical Enquiry, London: Routledge \& Kegan Paul [cit. por Norma y acción. Una investigación lógica, P. GARCÍA FERRERO (trad.), Madrid: Tecnos, 1979]. 